\author{
A. Zieliński, A. Dziadoń ${ }^{1}$, W. Serbiński, M. Jażdżewska \\ Gdańsk University of Technology, Faculty of Mechanical Engineering, Department of \\ Materials Science and Engineering, Gdansk, Poland, \\ ${ }^{1}$ Kielce University of Technology, Faculty of Mechatronics and Machine Building, \\ Department of Materials Science and Engineering, Kielce, Poland
}

\title{
SURFACE CRACKING OF LASER MELTED Ti-6Al-4V ALLOY
}

\begin{abstract}
The characteristic features of surface cracking observed after laser melting with $\mathrm{CO}_{2}$ and $\mathrm{Nd}$ :YAG laser were described. The cracks were always present, their length approaching some part of melted zone and scarcely dependent on laser melting conditions. The appearance of cracks was attributed mainly to martensitic transformation within the surface layer. The possible contribution of developed thermal stresses cannot be also excluded. The existence of cracks may be utilized for the enhancement of bone implant strength.
\end{abstract}

Key words: cracking, laser treatment, titanium alloys

\section{INTRODUCTION}

The modern biomaterials must fulfill a number of requirements. Among them, the extraordinary corrosion resistance in an environment of human body fluids is necessary. Therefore the titanium and its alloys are nowadays the most selected and investigated metallic materials destined for such applications.

There are a number of $\mathrm{Ti}$ alloys proposed as biomaterials for endoprostheses cones, with Ti-Al-V alloys being still the most popular. In order to increase the corrosion and wear resistance, a lot of technologies have been proposed. They include among others, an artificial oxidation. The chemical oxidation in acids, like nitric acid, and some concentrated hydroxides, electrochemical oxidation and thermal oxidation in vapour phase followed by heat treatment, have been proposed [1-10].

The laser treatment of Ti and its alloys is not widely accepted. Among others, the lasers have been applied to change the structure of surfacellayer increasing in such a way its corrosion resistance [11-13]. No appearance of cracks has been reported.

In this paper the previous results and possibilities to use the laser treatment for $\mathrm{Ti}$ alloy have been verified at different conditions with aim to especially examine the possible cracking of surface layer. 


\section{EXPERIMENTAL}

The Ti6Al4V alloy was melted. The laser treatment was made by two lasers: permanent work $\mathrm{CO}_{2}$ laser and Nd-YAG pulse laser. For $\mathrm{CO}_{2}$ laser the power input was ranged between 1.5 and $6 \mathrm{~kW}$, scan rate between 0.25 and $1 \mathrm{~m} / \mathrm{s}$, as environment the liquid nitrogen, water and air were imposed, and for the laser treatment in air some specimens were pre-heated between 200 and $550{ }^{\circ} \mathrm{C}$ just before laser melting. For Nd-YAG laser the power input was $150 \mathrm{~W}$, scan frequency $50 \mathrm{~Hz}$ and scan rate 0.25 to $4 \mathrm{~m} / \mathrm{min}$.; the melting was performed only in air.

\section{RESULTS AND DISCUSSION}

The results of performed tests are shown in Figs. 1-4. For every combination of tests parameters the view of the melted surface and cross-section are put together.

The cracks are evident to form at each condition. The depth of the crack is dependent on all variables. Generally, the higher power input and the lower scan rate, the longer cracks. The environment has also an effect: cracks are more significant during laser treatment in air and water. Pre-heating diminishes the cracking. The depth of the crack is always a significant portion of the melted zone and from this point of view, the laser melting in liquid nitrogen seems the most appropriate. The quantitative data are estimated and will be published in future.

Two possible sources of the cracks may be considered. The first is martensitic transformation following fast cooling even in water and air accompanied by an occurrence of high mechanical stresses. On the other hand, the cracking during martensitic transformation has not been reported for this alloy. Another possible source, high shear stresses appearing during solidification of this very hard and brittle alloy may release by formation of cracks. 

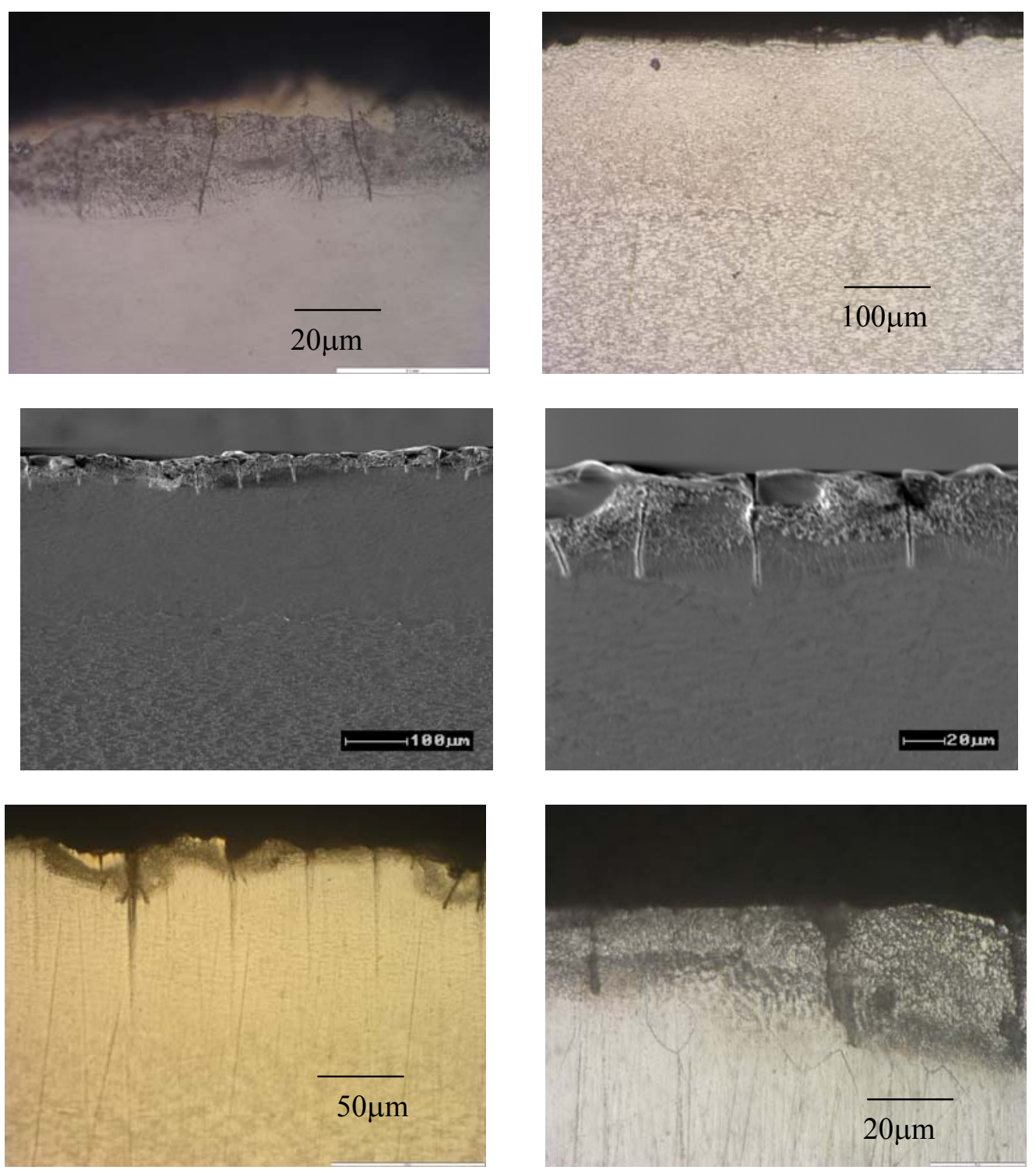

Fig. 1. Cracking of surface layers for specimens laser melted with $\mathrm{CO}_{2}$ laser in liquid nitrogen at scan rate $1 \mathrm{~m} / \mathrm{min}$ at power input (from top to the bottom): $3 \mathrm{~kW}, 4 \mathrm{~kW}, 5 \mathrm{~kW}$ and $6 \mathrm{~kW}$ 

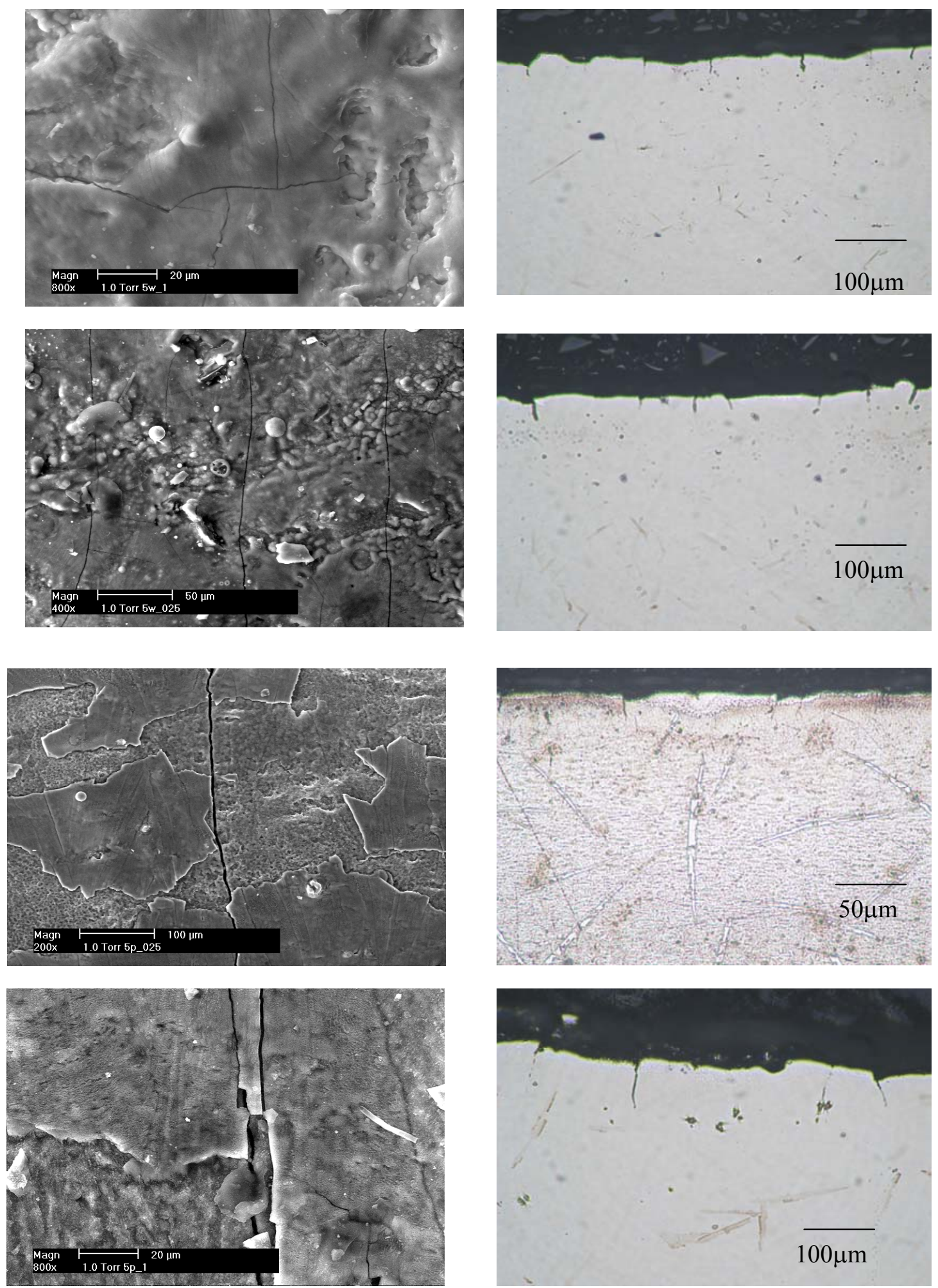

Fig. 2. Cracking of surface layers for specimens laser melted with $\mathrm{CO}_{2}$ laser at $5 \mathrm{~kW}$ (from top to the bottom): in water at scan rate $1 \mathrm{~m} / \mathrm{min}$.; in water at scan rate $0.25 \mathrm{~m} / \mathrm{min}$.; in air at scan rate $1 \mathrm{~m} / \mathrm{min}$.; in air at scan rate $0.25 \mathrm{~m} / \mathrm{min}$ 

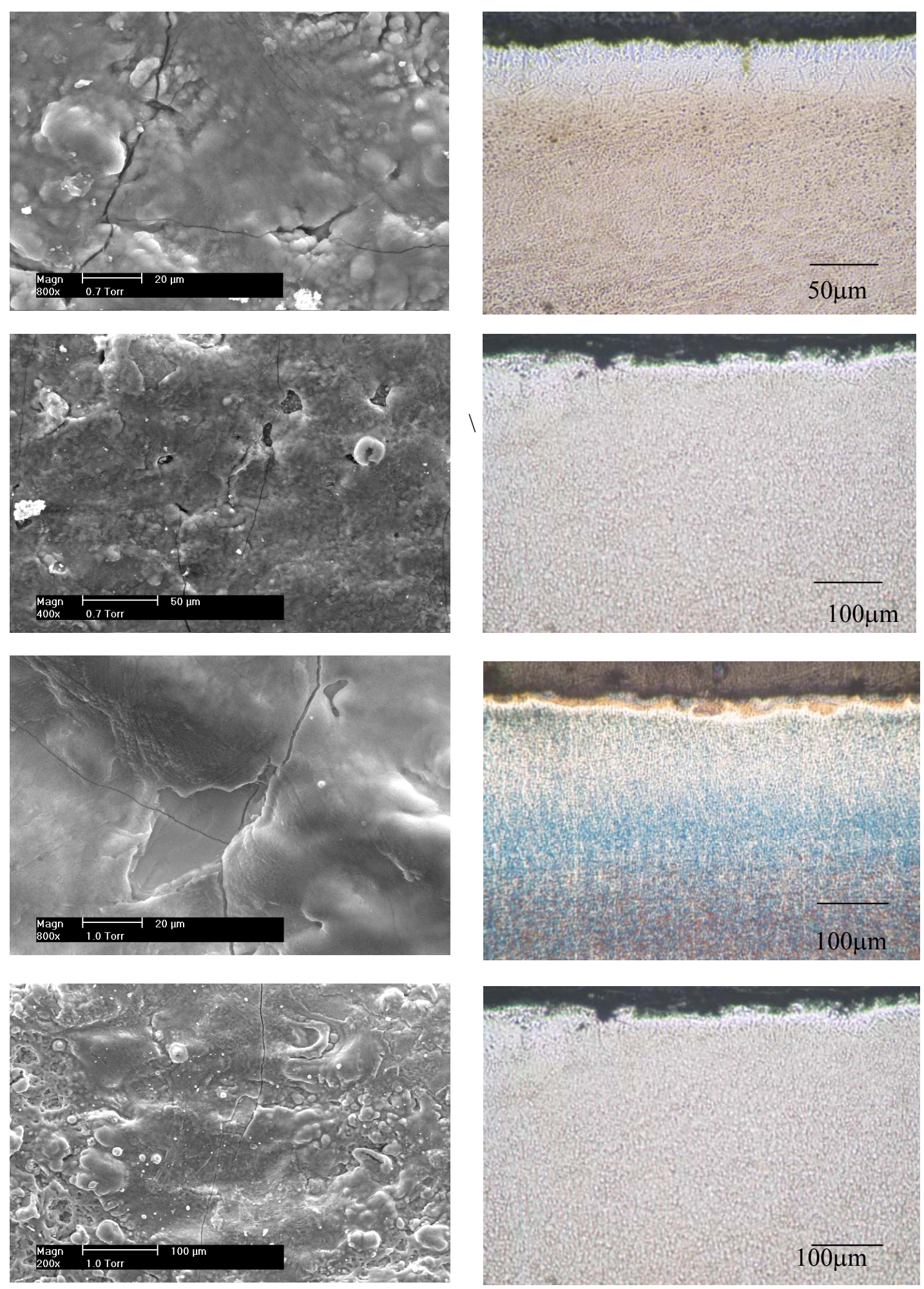

Fig. 3. Cracking of surface layers for specimens laser melted with $\mathrm{CO}_{2}$ laser in air at $5 \mathrm{~kW}$, at $1 \mathrm{~m} / \mathrm{min}$. scan rate and after pre-heating at temperature (from top to the bottom): $200,300,450$ and $550{ }^{\circ} \mathrm{C}$ 

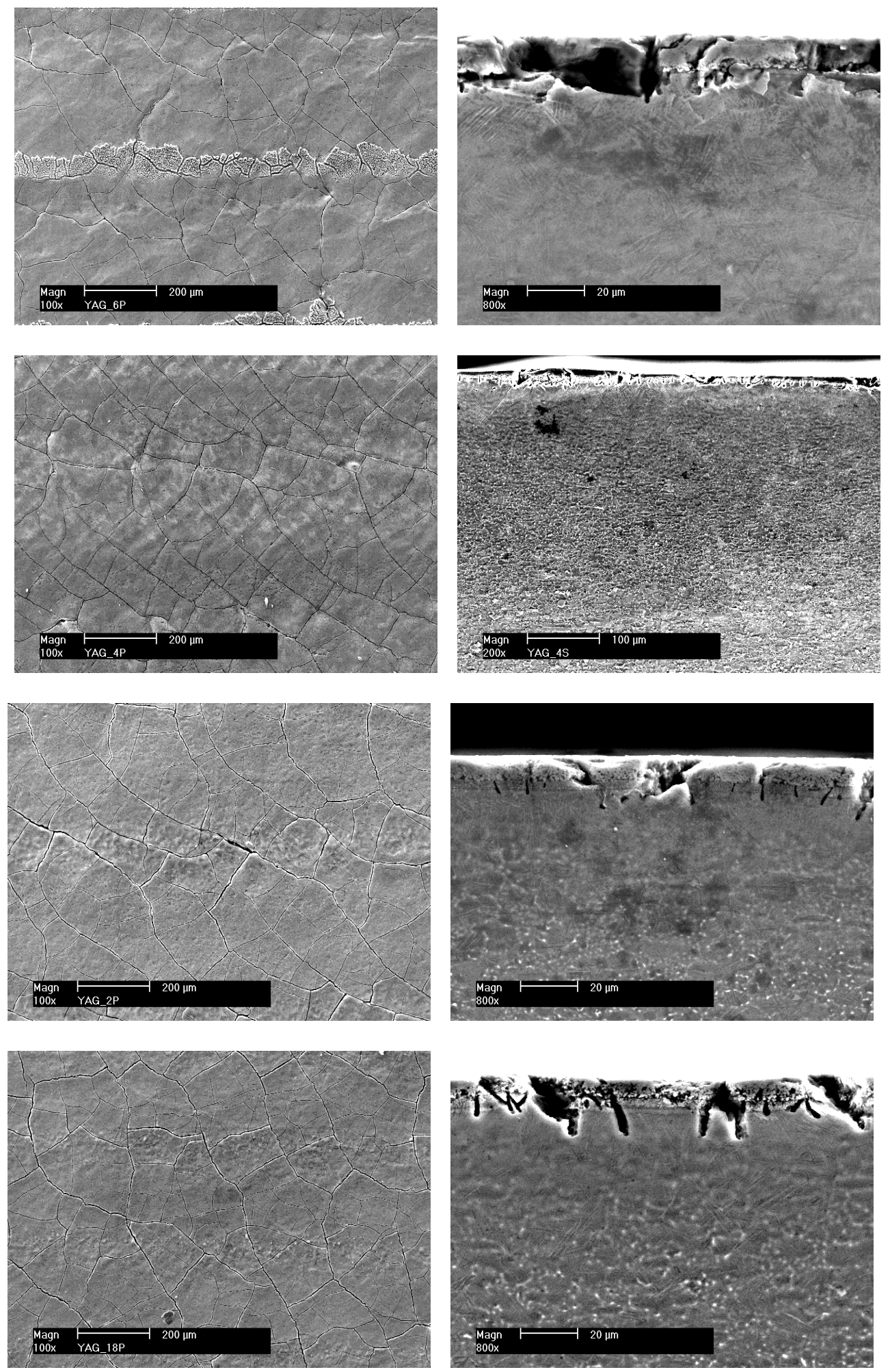

Fig. 4. Cracking of surface layers for specimens laser melted with $\mathrm{Nd}-\mathrm{YAG}$ laser at $150 \mathrm{~W}$ and $50 \mathrm{~Hz}$, with overlapping (from top to the bottom): $50 \%$, scan rate $0.25 \mathrm{~m} / \mathrm{min}$.; $50 \%$, scan rate $0.45 \mathrm{~m} / \mathrm{min}$.; $50 \%$, scan rate $0.65 \mathrm{~m} / \mathrm{min}$.; $30 \%$, scan rate $1 \mathrm{~m} / \mathrm{min}$ 

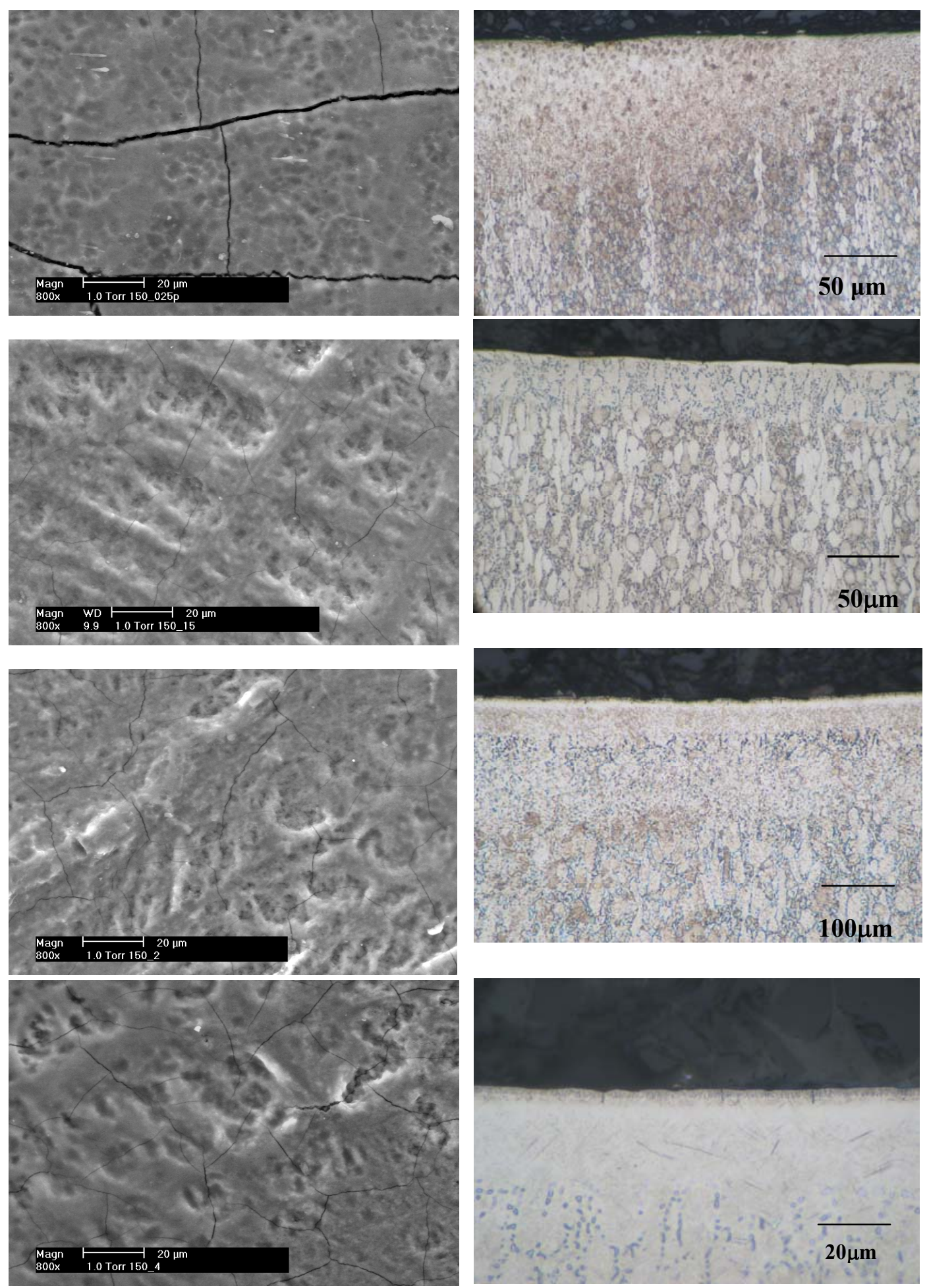

Fig. 5. Cracking of surface layers for specimens laser melted with Nd-YAG laser at $150 \mathrm{~W}$ and $50 \mathrm{~Hz}$, without overlapping (from top to the bottom) at scan rate: $0.25 \mathrm{~m} / \mathrm{min} ., 1.5 \mathrm{~m} / \mathrm{min}$., $2 \mathrm{~m} / \mathrm{min}, 4 \mathrm{~m} / \mathrm{min}$ 


\section{CONCLUSIONS}

The laser treatment of the Ti-6Al-4V alloy by both $\mathrm{CO}_{2}$ laser and Nd:YAG laser causes the melting and fast crystallization of surface layer accompanied by creation of perpendicular cracks from the surface to heat affected zone,

The appearance of cracks may be attributed to two processes: martensitic transformation and brittle cracking due to high internal stresses.

\section{ACKNOWLEDGMENTS}

The work has been supported by the Polish Ministry of Science and Higher Education as the research project No. 3 T08C 04929 entitled "Modification of structure and properties of surface layer of the Ti-6Al-4V alloy by surface melting in ultrafast cystallisation conditions".

\section{REFERENCES}

1. MacDonald D.E., Rapuano B.E., Deo N. i in.: Thermal and chemical modification of titanium-aluminum-vanadium implant materials: effects on surface propoerties, glycoprotein adsorption, and MG63 cell attachment. Biomaterials 25 (2004) 3135314.

2. Nishiguchi S., Kato H., Fujita H. i in.: Titanium metals form direct bonding to bone after alkali and heat treatments. Biomaterials 22 (2001) 2525-2533.

3. Yang B., Uchida M., Kim H.-M. i in.: Preparation of bioactive titanium metal via anodic oxidation treatment. Biomaterials 25 (2004) 1003-1010.

4. Wang X.-X., Yan W., Hayakawa S. i in.: Apatite deposition on thermally and anodically oxidized titanium surfaces in a simulated body fluid, Biomaterials, 24 (2003) 4631-4637.

5. Wang C.X., Wang M. and Zhou X., Nucleation and growth of apatite on chemically treated titanium alloy: an electrochemical impedance spectroscopy study, Biomaterials, 24 (2003) 3069-3077.

6. Wang X.-X., Hayakawa S., Tsuru K., Osaka A.: Bioactive titania gel layers formed by chemical treatment of $\mathrm{Ti}$ substrate with a $\mathrm{H}_{2} \mathrm{O}_{2} / \mathrm{HCl}$ solution. Biomaterials 23 (2002) 1353-1357.

7. Takeuchi M., Abe Y., Yoshida Y. i in.: Acid pretreatment of titanium implants. Biomaterials 24 (2003) 1821-2827.

8. Sul Y.-T., Johansson C.B., Petronis S. i in.: Characteristics of the surface oxides on turned and electrochemically oxidized pure titanium implants up to dielectric 
breakdown: the oxide thickness, micropore configuration, surface roughness, crystal structure and chemical composition. Biomaterials 23 (2002) 491-501.

9. Song W.-H., Jun Y.-K., Han Y., Hong S.-H.: Biomimetic apatite coatings on microarc oxidized titania. Biomaterials 25 (2004) 3341-3349.

10. Frauchiger V.M., Schlottig F., Gasser B., Textor M.: Anodic plasma-chemical treatment of CP titanium surfaces for biomedical applications. Biomaterials 25 (2004) 593-606.

11. Yue T.M., Cheung T.M., Man H.C.: The effects of laser surface treatment on the corrosion properties of Ti-6Al-4V alloy in Hank`s solution. J. Mater. Sci. Lett. 19 (2000) 205-208.

12. Yue T.M., Yu J.K., Mei Z., Man H.C.: Excimer laser surface treatment of Ti-6Al4V alloy for corrosion resistance enhancement. Mater. Lett. 52 (2002) 206-212.

13. Guillemot F., Prima E. $\mathrm{i}$ in.: Ultraviolet laser surface treatment fore biomedical applications of $\beta$ titanium alloys: morphological and structural characterization. Appl. Phys. A 77 (2003) 899-904. 